\title{
Desenvolvimento corporal de novilhas leiteiras suplementadas com minerais inorgânicos e orgânicos em pastejo na época das águas ${ }^{1}$
}

\author{
Body development of dairy heifers supplemented with inorganic minerals and organic \\ grazing during the rainy season
}

\author{
SIGNORETTI Ricardo Dias ${ }^{2 *}$; RESENDE, Flávio Dutra de ${ }^{2}$; DRUBI, Gabriel \\ Miranda $^{3}$; SOUZA, Fernando Henrique Meneguello de ${ }^{3}$; DIB, Vanessa ${ }^{4}$; OLIVEIRA, \\ Elisa Marcela de ${ }^{3}$
}

\author{
${ }^{1}$ Projeto financiado pelo CNPq e pela Tortuga Cia Zootecnia Agrária. \\ ${ }^{2}$ Agência Paulista de Tecnologia dos Agronegócios, Polo Regional Alta Mogiana, Colina ,São Paulo, Brasil. \\ ${ }^{3}$ Universidade Estadual Paulista, Faculdade de Ciências Agrárias e Veterinária, Programa de Pós- \\ Graduação em Zootecnia, Jaboticabal, São Paulo, Brasil. \\ *Endereço para correspondência: signoretti@apta.sp.gov.br
}

\section{RESUMO}

Objetivou-se avaliar os efeitos da suplementação com fontes de minerais inorgânicos e orgânicos, na época das águas do ano, sobre o desempenho de novilhas leiteiras mestiças Gir x Holandês, com idade média de $13,6 \pm 2,9$ meses e peso corporal inicial de $176,8 \pm 10,1 \mathrm{~kg}$, distribuídas em delineamento de blocos ao acaso, sendo considerado o módulo de pastejo (dois módulos/tratamento) como tratamento (fontes de minerais inorgânicos e orgânicos) e animais como repetição (16 animais/tratamento) em pastagem de Brachiaria brizantha (Hochst. ex. A. Rich.) Stapf. cv. Marandu, manejada em sistema intermitente. Ao final de cada ciclo de pastejo (42 dias) os animais foram pesados e mensurados quanto à altura na cernelha e perímetro torácico e, o peso corporal médio do lote foi usado para os cálculos de ajuste de carga. Com relação à oferta de forragem em matéria seca, não houve diferença entre os tratamentos, mas sim sobre os ciclos. A oferta de forragem média para os ciclos foi de $12 \mathrm{~kg}$ matéria seca $/ 100 \mathrm{~kg}$ de peso corporal, com taxa de lotação de 4,19UA/ha. Não foram observados efeitos das fontes de minerais inorgânicos e orgânicos sobre o ganho médio diário de peso corporal e nas mensurações do perímetro torácico e na altura da cernelha. O manejo correto da pastagem na época das águas e a suplementação mineral adequada proporcionou excelente desempenho de novilhas leiteiras com ganhos médios de
0,680 kg/dia. O desempenho de novilhas leiteiras recriadas a pasto foi semelhante quando suplementadas com fontes minerais inorgânicos ou orgânicos.

Palavras-chave: ganho de peso, manejo de pastagem, oferta de forragem, recria de novilhas

\section{SUMMARY}

The objective was to evaluate the effects of supplementation with sources of inorganic minerals and organic, in the rainy season of the year on the performance of dairy crossbred Gir $\mathrm{x}$ Holstein, with a mean age of $13.6 \pm 2.9$ months and body weight averaging $176.8 \pm$ $10.1 \mathrm{~kg}$ were assigned at random block design, the module (two module/treatment) is considered as the grazing treatment (inorganic minerals and organic sources) and animals such as repetition (16 animals / treatment) in pasture Brachiaria brizantha (Hochst. ex. A. Rich.) Stapf. cv. Marandu, managed under rotational grazing system. At the end of each grazing cycle (42 days) the animals were weighed and measured for height at withers and girth and the body weight average batch was used for calculation of load adjustment. With respect to the forage available did not differ between treatments, but on the cycles. The average forage available for the cycles was $12 \mathrm{~kg}$ dry matter $/ 100 \mathrm{~kg}$ body weight with stocking rate of 
4.19UA/ha. There were no effects of inorganic minerals and organic sources on the average daily gain of body weight and measurements in the height at withers and the girth. The correct management of grazing in the rainy season and the appropriate mineral supplementation provided an excellent performance of dairy heifers with average gains of $0.680 \mathrm{~kg} /$ day. The performance of dairy heifers rearing pasture was similar when supplemented with organic or inorganic mineral sources.

Keywords: forage available, pasture management, rearing of heifers, weight gain

\section{INTRODUÇÃO}

O objetivo na criação de novilhas de reposição é conseguir crescimento adequado, de forma que esses animais tenham precocidade na idade ao primeiro parto o mais cedo possível, a baixo custo, e que possam substituir prontamente vacas descartadas do rebanho em lactação retornando $\mathrm{o}$ investimento do produtor em alimentação, mão de obra, entre outras, pois a recria representa de 20 a $25 \%$ do custo na atividade leiteira (PERES et al., 2008).

No Brasil Central, onde a sazonalidade é marcante, com maior produção no período das águas (70 a 80\%), o manejo racional de pastagem é fundamental para o melhor aproveitamento desta forragem disponível de qualidade. Segundo Reis et al. (2009), não há diferença significativa quanto aos níveis nutricionais para forrageiras oferecidas na forma de pastejo sob lotação intermitente. Sendo assim, para o melhor desempenho, deve-se garantir a oferta adequada à necessidade animal de matéria seca.

Portanto, há necessidade de se obter ganhos em produtividade, minimizando os efeitos negativos da sazonalidade de forrageiras tropicais (VILLELA et al., 2010). Por isso, a suplementação mineral é considerada obrigatória em sistemas de produção de bovinos leiteiros.

A correta suplementação mineral é de suma importância para a fase de crescimento de bovinos leiteiros, principalmente por causa da formação dos tecidos ósseo e muscular. Além disso, os suplementos minerais devem conter as melhores fontes de macro e microelementos para o maior incremento na produção e, além disso, deve ser de elevada biodisponibilidade e livres de contaminantes (FILAPPIE et al., 2005; Peixoto et al., 2005).

Neste sentido, o uso de microelementos minerais na forma orgânica na dieta dos bovinos pode proporcionar aumento da biodisponibilidade desses ingredientes em relação a fontes inorgânicas com melhoria na produtividade de forma geral, bem como nos índices de fertilidade dos animais, porém a biodisponibilidade destas fontes de minerais é influenciada por diversos fatores, tais como: tamanho de partícula, reatividade e solubilidade, origem do precursor, grau de calcinação e ligantes orgânicos, o que pode contribuir para as variações nas respostas de desempenho dos animais (SPEARS, 2003; ZANETTI et al., 2003).

Objetivou com este trabalho avaliar a suplementação com minerais inorgânicos e orgânicos na época das águas sobre o desenvolvimento corporal de novilhas mestiças leiteiras, buscando-se antecipar a entrada dos animais em sua fase produtiva.

\section{MATERIAL E MÉTODOS}

O experimento foi conduzido na unidade de pesquisa do Pólo Regional de Desenvolvimento Tecnológico dos Agronegócios da Alta Mogiana 
(PRDTA - Alta Mogiana), em Colina SP, órgão da Agência Paulista de Tecnologia dos Agronegócios, da Secretaria de Agricultura e Abastecimento do Estado de São Paulo.

O PRDTA - Alta Mogiana está localizado no município de Colina, Estado de São Paulo (latitude de $20^{\circ} 43^{\prime}$ $05^{\prime \prime} \mathrm{S}$; longitude $\left.48^{\circ} 32^{\prime} 38^{\prime \prime} \mathrm{W}\right)$. O clima da região é do tipo AW (segundo classificação de Köppen.). O solo do local é classificado como latossolo vermelho-escuro, fase arenosa, com topografia quase plana e de boa drenagem.

Durante o período experimental $(09 / 10 / 2006$ a 06/05/2007) a precipitação pluviométrica acumulada foi de $1186,20 \mathrm{~mm}$ e a temperatura mínima e máxima, em média, foi de 31,50 e $19,74^{\circ} \mathrm{C}$, respectivamente (Figura 1).

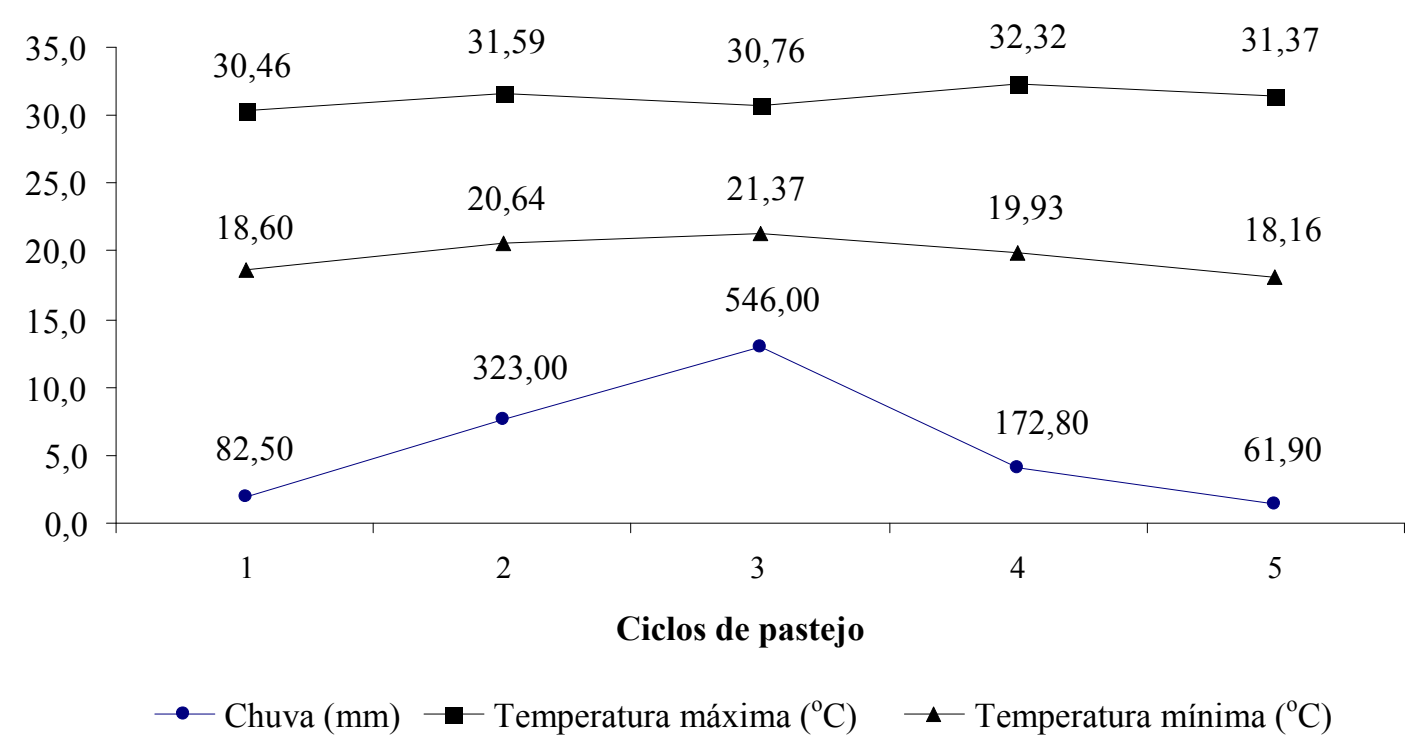

Figura 1. Valores médios acumulados de chuva, em mm, temperatura média diária, máxima e mínima, em ${ }^{\circ} \mathrm{C}$, em função dos diferentes ciclos de pastejo. Ciclos de pastejo $1=09 / 10 / 06$ a $19 / 11 / 06 ; 2=20 / 11 / 06$ a $31 / 12 / 06 ; 3=$ $01 / 01 / 07$ a $11 / 02 / 07 ; 4=12 / 02 / 07$ a $25 / 03 / 07$ e $5=26 / 03 / 07$ a $06 / 05 / 07$

A área experimental, de 7,28ha, foi formada em dezembro de 2005 com a forrageira Brachiaria brizantha (Hochst. ex. A. Rich.) Stapf. cv. Marandu, posteriormente subdividida em quatro módulos de pastejo com área de 1,82ha. Cada módulo apresentava seis piquetes que foram manejados sob o método de lotação intermitente, além de área de lazer central de $2800 \mathrm{~m}^{2}$, contendo bebedouro, saleiro coberto e sombreamento artificial de $40 \mathrm{~m}^{2}$ tipo sombrite $(70 \%)$.
A análise de solo foi realizada antes do início do período experimental e os valores médios de fósforo, da matéria orgânica e da saturação de bases nos módulos de pastejo $1 ; 2 ; 3$ e 4 foram, respectivamente, $6 ; 6 ; 7$ e $5 \mathrm{mg} / \mathrm{dm}^{3} ; 23$; $22 ; 21$ e $22 \mathrm{~g} / \mathrm{dm}^{3} ; 39 ; 50 ; 39$ e $40 \%$. A calagem (calcário dolomítico - PRNT $=88$ ) e a fosfatagem (fosfato reativo $35 \%$ de Ca e $29 \%$ de $\mathrm{P}$ total, sendo $9 \%$ solúvel). Conforme os resultados da análise mencionados acima o solo foi corrigido para elevar a $\% \mathrm{~V}$ para $60 \% \mathrm{e}$ foi aplicado $100 \mathrm{~kg}$ de $\mathrm{P}_{2} \mathrm{O}_{5}$ por ha. 
Foram utilizadas 32 novilhas mestiças Gir x Holandês (com predominância de grau de sangue $3 / 4$ a 7/8 Holandês) com idade inicial de 13,6 $\pm 2,9$ meses e peso corporal (PC) de 176,8 $\pm 10,1 \mathrm{~kg}$, selecionadas em função do peso inicial. Além destas, foi utilizado número variável de animais reguladores contemporâneos, para manutenção da oferta de forragem semelhante entre os módulos de pastejo.

Ao início da fase experimental, em $09 / 10 / 2006$, os animais foram pesados, identificados individualmente através de brincos plásticos, desverminados e submetidos a 30 dias de adaptação ao ambiente criatório.

Os animais foram manejados em sistema de pastejo intermitente, com sete dias de ocupação e 35 dias de descanso em cada piquete, perfazendo ciclos de pastejo de 42 dias. Foram realizadas adubações nitrogenadas ao final de cada período de ocupação, sendo utilizados $50 \mathrm{~kg}$ de nitrogênio/ha (uréia) em cada ciclo. Durante a época das águas, 210 dias, foram realizado cinco adubações, totalizando $250 \mathrm{~kg}$ de nitrogênio/ha/ano. Ao final de cada ciclo os animais foram pesados pela manhã, sem jejum prévio, sendo o peso médio do lote usado para os cálculos de ajuste de carga.

Os tratamentos consistiram de animais recebendo suplemento com fontes de minerais inorgânicos (formulado utilizando-se fontes inorgânicas de minerais: enxofre em pó; sulfato de cobre; sulfato ou oxido de zinco e selenito de sódio) ou orgânicos (formulado com minerais $100 \%$ na forma de carbo amino fosfo quelatos: enxofre; cobre; manganês; zinco; cromo e selênio), conforme composição apresentada na Tabela 1 .

Os suplementos foram fornecidos em quatro cochos coletivos, “ad libitum” (8 animais $/ 3,2 \mathrm{~m}$ lineares de cocho em cada módulo de seis piquetes) e o consumo foi monitorado e a quantidade oferecida e as sobras registradas ao final de cada semana.

Tabela 1. Fórmula do suplemento mineral e os níveis de garantia por $\mathrm{kg}$ do produto

\begin{tabular}{lrc}
\hline $\begin{array}{l}\text { Elemento } \\
\text { mineral }\end{array}$ & Nível & Unidade \\
\hline Cálcio & 138,0 & $\mathrm{~g} / \mathrm{kg}$ \\
Fósforo & 88,0 & $\mathrm{~g} / \mathrm{kg}$ \\
Sódio & 11,7 & $\mathrm{~g} / \mathrm{kg}$ \\
Cloro & 18,3 & $\mathrm{~g} / \mathrm{kg}$ \\
Enxofre & 20,0 & $\mathrm{~g} / \mathrm{kg}$ \\
Cobre & $1.200,0$ & $\mathrm{mg} / \mathrm{kg}$ \\
Zinco & $3.400,0$ & $\mathrm{mg} / \mathrm{kg}$ \\
Selênio & 12,0 & $\mathrm{mg} / \mathrm{kg}$ \\
Cromo & 30,0 & $\mathrm{mg} / \mathrm{kg}$ \\
Iodo & 70,0 & $\mathrm{mg} / \mathrm{kg}$ \\
Cobalto & 50,0 & $\mathrm{mg} / \mathrm{kg}$ \\
\hline Fonte: Tortuga Companhia Zootécnica Agrária.
\end{tabular}

O número de animais por lote foi ajustado conforme a massa de forragem disponível nos piquetes. A massa de forragem foi determinada utilizando $o$ método direto de amostragem com quadrado metálico de 1,0 x $1,0 \mathrm{~m}$ lançado ao acaso e todo o material do local demarcado pelo mesmo foi cortado rente ao solo. Cinco amostras por piquete foram coletadas em todos os módulos, sendo posteriormente pesadas e suas médias calculadas para determinar a massa de forragem disponível na matéria natural. Para cada módulo, foi feita uma composta das amostras coletadas, secas em estufa de ventilação forçada a $65^{\circ} \mathrm{C}$ por $72 \mathrm{~h}$ e moída em moinho de faca utilizando-se peneira com crivos de $1,0 \mathrm{~mm}$ na malha. As avaliações das características do pasto (módulos) foram realizadas a cada 14 dias. Neste caso, o critério utilizado foi avaliar os piquetes impares no 
primeiro ciclo de pastejo e depois os pares de cada módulo de pastejo, sucessivamente. Durante as coletas, também foram avaliadas a altura do dossel forrageiro na entrada e saída dos animais com auxílio de régua graduada $(\mathrm{cm})$.

De acordo com a disponibilidade de massa seca (MS) de pasto e o peso médio dos animais determinou-se a oferta de matéria seca e preconizou-se trabalhar com oferta de $12 \mathrm{~kg}$ de $\mathrm{MS} / 100 \mathrm{~kg}$ de peso corporal.

A técnica utilizada para manter o consumo da forragem disponível sem submetê-la a sub ou superpastejo foi o método "put and take", ou seja, carga fixa com taxa de lotação variável. Os animais utilizados para ajuste da oferta de forragem foram mantidos em área anexa próxima à área experimental, onde tinham a disposição a mesma gramínea e recebiam sal mineral e quando foram utilizados passavam por todos os piquetes experimentais.

Para determinação dos componentes da gramínea, utilizou-se quadrado metálico de $0,25 \times 0,25$, seguindo a técnica do método direto descrito anteriormente. Destas amostras separou-se a lâmina foliar (potencialmente consumida pelos animais) da bainha foliar, colmo e inflorescência (potencialmente não consumidos), além do material senescente e foram submetidas ao processo de pré-secagem a $65^{\circ} \mathrm{C}$, por $72 \mathrm{~h}$, em estufa de ventilação forçada. Após a secagem o material foi moído em moinho de faca utilizando-se peneira com crivos de $1,0 \mathrm{~mm}$ na malha e armazenados em recipientes apropriados para análises posteriores.

Os teores de matéria seca (MS), proteína bruta (PB) e cinzas (MM) foram determinados conforme a metodologia descrita por Silva \& Queiroz (2002) e os teores de fibra em detergente neutro (FDN) e fibra em detergente ácido (FDA) foram avaliados pelo método sequencial descrito por Van Soest et al. (1991), com as amostras submetidas à digestão em solução de detergente por $40 \mathrm{~min}$ em autoclave a $111^{\circ} \mathrm{C}$ e $0,5 \mathrm{~atm}$ (DESCHAMPS, 1999).

Ao final de cada ciclo de pastejo (42 dias), os animais foram pesados, sem jejum prévio, e mensurados quanto à altura na cernelha e o perímetro torácico, no período da manhã. Para as medições de altura de cernelha e perímetro torácico foram feitas três medições, com régua graduada, tomando-se o valor médio como medida da variável analisada.

Os parâmetros relacionados ao desempenho animal foram avaliados através de delineamento de bloco casualizado, sendo considerado o módulo de pastejo (dois módulos/tratamento) e como tratamento (fontes de mineral no suplemento (orgânico e inorgânico)) e o animal como repetição (16 animais/tratamento, ou seja, 8 animais/módulo/tratamento). Já no caso das avaliações de forragem a unidade experimental foi o piquete (6 piquetes/módulo). O modelo proposto incluiu efeito de tratamento (fontes de mineral orgânico e inorgânico), ciclo de pastejo e interação tratamento-ciclo de pastejo conforme equação abaixo.

$\mathrm{Y}_{\mathrm{ijk}}=\mu+\mathrm{T}_{\mathrm{i}}+\mathrm{B}_{\mathrm{j}}+\mathrm{CP}_{\mathrm{k}}+(\mathrm{T} \text { x CP })_{\mathrm{ik}}+$ $\mathrm{e}_{\mathrm{ijk}}$, em que,

$\mathrm{Y}_{\mathrm{ijk}}=$ Variável analisada

$\mu=$ média geral

$\mathrm{T}_{\mathrm{i}}=$ efeito do tratamento $\cdots \cdots$, sendo $\mathrm{i}=1$

- sal mineral inorgânico e 2 sal mineral orgânico;

$\mathrm{B}_{\mathrm{j}}=$ Efeito do bloco ${ }^{\mathrm{j}} \mathrm{j}$, sendo $\mathrm{j}=1$ e 2 ;

$\mathrm{CP}_{\mathrm{k}}=$ Efeito do ciclo de pastejo " $\mathrm{k}$, sendo $\mathrm{k}=1,2,3,4$ e 5 ;

$\left(\begin{array}{lll}\mathrm{T} & \mathrm{CP}\end{array}\right)_{\mathrm{ik}}=$ interação entre $\mathrm{o}$ tratamento 1 "."e o ciclo de pastejo " $k "$

$\mathrm{e}_{\mathrm{ijk}}=$ erro aleatório residual 
As variáveis relativas ao desenvolvimento corporal foram submetidas à análise da variância, considerando os efeitos de fontes de mineral utilizado (orgânico e inorgânico) e as relativas as características quantitativas e qualitativas do pasto os efeitos dos ciclos de pastejo (1 a 5), as quais foram analisadas como medidas repetidas no tempo, mediante o uso de PROC MIXED do SAS 8.0 (1999), sendo as médias comparadas pelo teste de Tukey a $5 \%$ de probabilidade.

\section{RESULTADOS E DISCUSSÃO}

Não houve efeito $(\mathrm{P}>0,05)$ para nenhuma das variáveis estudadas das fontes de minerais e da interação das fontes e dos ciclos de pastejo, tanto nas avaliações na parte aérea como da lâmina foliar do capim Marandu (Tabela 2).

Tabela 2. Porcentagem média de matéria seca (MS), matéria mineral (MM), proteína bruta $(\mathrm{PB})$, fibra em detergente neutro (FDN) e fibra em detergente ácido (FDA), (base da matéria seca) da gramínea (parte aérea e lâmina foliar) em função da fonte de minerais (FM) inorgânica (FI) ou orgânica (FO) nos ciclos de pastejo, durante a época das águas

\begin{tabular}{|c|c|c|c|c|c|c|c|c|c|}
\hline \multirow{2}{*}{ Variável } & \multicolumn{2}{|c|}{ FM } & \multicolumn{5}{|c|}{ Ciclos $^{1}$} & \multirow{2}{*}{ Média } & \multirow{2}{*}{$\mathrm{CV}^{2}$} \\
\hline & FI & FO & 1 & 2 & 3 & 4 & 5 & & \\
\hline \multicolumn{10}{|c|}{ Parte aérea ${ }^{3}$} \\
\hline MS & 30,5 & 30,4 & $45,0^{\mathrm{a}}$ & $24,6^{\mathrm{d}}$ & $21,7^{\mathrm{e}}$ & $27,9^{\mathrm{c}}$ & $33,2^{b}$ & 30,3 & 19,5 \\
\hline MM & 7,4 & 8,1 & $8,0^{\mathrm{b}}$ & $9,8^{\mathrm{ab}}$ & $5,9^{c}$ & $10,6^{\mathrm{a}}$ & $4,4^{\mathrm{d}}$ & 7,2 & 34,8 \\
\hline PB & 6,0 & 5,5 & $5,6^{\mathrm{c}}$ & $6,5^{\mathrm{a}}$ & $5,8^{\mathrm{b}}$ & $5,2^{\mathrm{c}}$ & $5,6^{\mathrm{c}}$ & 5,7 & 18,5 \\
\hline FDN & 66,5 & 66,4 & $68,3^{\mathrm{a}}$ & $64,9^{\mathrm{c}}$ & $66,4^{\mathrm{ab}}$ & $66,1^{\mathrm{ab}}$ & $66,7^{\mathrm{ab}}$ & 66,5 & 3,85 \\
\hline FDA & 39,8 & 39,8 & $44,3^{\mathrm{a}}$ & $38,0^{\mathrm{b}}$ & $38,5^{\mathrm{b}}$ & $38,5^{\mathrm{b}}$ & $39,7^{\mathrm{ab}}$ & 39,8 & 12,7 \\
\hline \multicolumn{10}{|c|}{ Lâmina foliar } \\
\hline MS & 30,6 & 30,2 & $44,7^{\mathrm{a}}$ & $24,3^{\mathrm{c}}$ & $21,8^{d}$ & $27,8^{\mathrm{c}}$ & $33,3^{b}$ & 30,2 & 19,7 \\
\hline MM & 7,93 & 7,69 & $9,1^{\mathrm{a}}$ & $10,2^{\mathrm{a}}$ & $5,8^{\mathrm{b}}$ & $8,9^{\mathrm{a}}$ & $5,1^{\mathrm{b}}$ & 7,4 & 30,4 \\
\hline PB & 10,3 & 10,0 & $10,9^{\mathrm{ab}}$ & $10,0^{\mathrm{bc}}$ & $9,7^{\mathrm{c}}$ & $8,9^{\mathrm{c}}$ & $11,2^{\mathrm{a}}$ & 10,3 & 15,3 \\
\hline FDN & 59,7 & 58,6 & $54,5^{\mathrm{c}}$ & $59,0^{\mathrm{b}}$ & $61,7^{\mathrm{a}}$ & $61,4^{\mathrm{a}}$ & $59,1^{\mathrm{b}}$ & 59,2 & 4,4 \\
\hline FDA & 30,6 & 29,1 & $25,8^{\mathrm{c}}$ & $31,9^{\mathrm{a}}$ & $32,3^{\mathrm{a}}$ & $30,9^{\mathrm{ab}}$ & $28,3^{\mathrm{b}}$ & 29,9 & 11,4 \\
\hline
\end{tabular}

Médias seguidas da mesma letra minúscula na linha não diferem entre si pelo teste Tukey $(\mathrm{P}>0,05)$.

${ }^{1}$ Ciclos de pastejo $=1: 09 / 10 / 06$ a 19/11/06; 2: 20/11/06 a 31/12/06, 3: 01/01/07 a 11/02/07; 4: 12/02/07 a 25/03/07 e 5: 26/03/07 a 06/05/07.

${ }^{2} \mathrm{CV}=$ coeficiente de variação.

${ }^{3}$ Material coletado a rente ao solo, incluindo todos os componentes da planta (lâmina foliar + bainha + colmo + inflorescência).

Houve efeito $(\mathrm{P}<0,05)$ dos ciclos de pastejo para os teores de MS, MM, FDN e FDA na parte aérea da planta. Os teores de MS e FDA reduziram no decorrer do período avaliado (Tabela 2). $\mathrm{O}$ teor de $\mathrm{PB}$ foi afetado pelos ciclos de pastejo, sendo maior no segundo ciclo de pastejo e menor no quarto ciclo de pastejo (Tabela 2). Benett et al. (2008) encontraram teor de $\mathrm{PB}$ de $9,0 \%$ na Brachiaria brizantha, superior ao encontrado neste estudo. Segundo 
Lazzarini et al. (2009) e Sampaio et al. (2009), com os teores de PB das forrageiras inferiores a $7 \%$ ocorre redução na digestão da mesma devido a inadequados níveis de nitrogênio para os microrganismos do rúmen, diminuindo sua população e, consequentemente, redução da digestibilidade e da ingestão da massa seca. Assim, teor mais alto de PB é necessário para $\mathrm{O}$ atendimento das exigências proteicas do organismo animal. No entanto, o teor de PB na lâmina foliar, neste estudo foi, em média, de $10,3 \%$ PB e a seleção deste material realizada pelos animais promoveu maior aporte de $\mathrm{PB}$ na dieta dos mesmos implicando em melhor desempenho animal.

Com relação o teor de FDA foi, em média, de 39,8\%, superior ao relatado por Benetti et al. (2008) de 34,06\% para o capim Marandu. Observou-se que houve efeito $(\mathrm{P}<0,05)$ dos ciclos de pastejo para os teores de MS, MM, PB, FDN e FDA na lâmina foliar da planta. Houve redução nos teores de MS, MM e PB e aumento nos teores de FDN e FDA no decorrer período avaliado (Tabela 2). A redução na composição química das forragens com o avanço do estádio de crescimento está associada principalmente com a redução dos teores de PB dos colmos e das folhas e aumento da fração FDN e FDA, com a consequente redução na digestibilidade da MS, afetando negativamente o desempenho animal.

Entretanto, é possível se observar que o valor nutritivo do material ingerido pelos animais era ainda superior (Tabela 2 - lâmina foliar), pois as características do pasto não representam as características da forragem realmente consumida pelos animais, devido ao comportamento seletivo desses em pastejo, uma vez que apresentam preferência por determinadas partes das plantas (lâmina foliar). Por esse motivo, a composição da dieta frequentemente difere da composição do pasto, em termos de composição botânica e química (BRÂNCIO et al., 2003). Nesse sentido, a dieta colhida pelo animal normalmente apresenta maiores teores de proteína bruta e menores teores de FDN (BRÂNCIO et al., 2003). O mesmo foi verificado no presente estudo, pois ao avaliar os teores de PB e FDN da lâmina foliar (Tabela 2) observaram-se valores médios de 10,3 e $59,2 \%$, respectivamente.

Não foram observadas diferenças $(\mathrm{P}<0,05)$ em relação às condições do pasto em função das fontes de minerais (orgânica e inorgânica), com exceção da $\mathrm{OF}$, que foi maior no tratamento com fonte de mineral orgânica (Tabela 3). Os valores médios de massa de forragem foram de 6,93t de $\mathrm{MS} / \mathrm{ha}$, propiciando ofertas de massa de forragem de $12 \mathrm{~kg}$ de $\mathrm{MS} / 100 \mathrm{~kg}$ de PC. Nesse sentido, Hodgson (1990) sugeriu o valor de 10 a $12 \mathrm{~kg}$ de $\mathrm{MS} / 100 \mathrm{~kg}$ de $\mathrm{PC}$, como sendo a oferta na qual o consumo de MS de pasto é máximo, estando esse valor próximo ao obtido no presente trabalho.

Os percentuais médios de colmo/bainha, folha e material senescente, foram de 31,$3 ; 29,8$ e $38,9 \%$; respectivamente. A oferta média de folhas, em $\mathrm{kg}$ de MS/100kg PC, foi de 3,12 (Tabela 3). Sabe-se que a massa de forragem pode limitar o consumo dos animais em pastejo, no entanto, a quantidade de MS total foi sempre superior a $2.000 \mathrm{~kg} / \mathrm{ha}$ de MS total (Tabela 3), pois Flores et al. (2008) e Paula et al. (2010) confirmaram que a massa de forragem total inferior a $2.000 \mathrm{~kg} / \mathrm{ha}$ pode limitar o consumo voluntário dos animais em pastejo, e, com isso, obter-se-ia um desempenho abaixo do esperado.

Entretanto, segundo Euclides (2000), quando há grande acúmulo sazonal de 
material morto, o consumo de forragem pelo animal não está correlacionado ao total de forragem disponível, mas, sim, às massas de MS verde e de MS da lâmina foliar, as quais devem estar acima de $1.100 \mathrm{~kg} / \mathrm{ha}$, valor superior foi encontrado no presente estudo (Tabela 3 ).

A pastagem foi manejada de forma a propiciar a mesma oferta de MS aos animais (12kgMS/100kg PC), pois o objetivo foi de avaliar as fontes de minerais inorgânicos e orgânicos no desempenho de novilhas leiteiras.
Avaliando-se a altura do dossel, durante a entrada e saída dos animais, verificouse que a mesma não foi influenciada pelas fontes de minerais, sendo os valores médios observados de 53,3 e $32,1 \mathrm{~cm}$, respectivamente. Neste caso, uma maior altura do dossel na saída dos piquetes $(32,1 \mathrm{~cm})$ pode ter colaborado para obtenção de maiores proporções de material senescente $(38,9 \%)$ observado na época das águas (Tabela 3).

Tabela 3. Valores médios de massa de forragem, em t/ha, proporções de colmo/bainha, folha e material senescente (M Sen), altura do dossel (AD) na entrada e saída, em $\mathrm{cm}$, oferta de forragem (OF) e oferta de folhas (OFF), em $\mathrm{kg}$ de $\mathrm{MS} / 100 \mathrm{~kg}$ de PC e a taxa de lotação (TL), em UA ha ${ }^{-1}$, da pastagem de Brachiaria brizantha, cv. Marandu durante a época das águas em função da fonte de minerais (FM) inorgânica (FI) ou orgânica (FO)

\begin{tabular}{|c|c|c|c|c|c|c|c|}
\hline \multirow{2}{*}{ Variáveis } & \multicolumn{2}{|c|}{ FM } & \multirow{2}{*}{ Média } & \multirow{2}{*}{$\mathrm{CV}^{2}$} & \multicolumn{3}{|c|}{$\mathrm{P}<\mathrm{F}^{1}$} \\
\hline & FI & $\mathrm{FO}$ & & & FM & $\mathrm{C}$ & $\mathrm{FM}^{*} \mathrm{C}$ \\
\hline Massa de forragem & 7,03 & 6,83 & 6,93 & 18,9 & 0,47 & $* *$ & 0,17 \\
\hline Colmo/bainha (\%) & 32,2 & 30,4 & 31,3 & 32,4 & 0,50 & $* *$ & 0,61 \\
\hline Folha (\%) & 30,3 & 29,3 & 29,8 & 36,3 & 0,66 & $* *$ & 0,84 \\
\hline M Sen $(\%)$ & 37,5 & 40,3 & 38,9 & 36,6 & 0,41 & $* *$ & 0,67 \\
\hline $\mathrm{AD}$ entrada $(\mathrm{cm})$ & 54,6 & 51,9 & 53,3 & 14,3 & 0,12 & $* *$ & 0,22 \\
\hline AD saída (cm) & 32,9 & 31,3 & 32,1 & 18,1 & 0,27 & $* *$ & 0,88 \\
\hline OF & $11,3 b$ & $12,6 \mathrm{a}$ & 12,0 & 24,5 & $*$ & $* *$ & 0,68 \\
\hline OFF & 2,94 & 3,30 & 3,12 & 28,9 & 0,12 & $*$ & 0,44 \\
\hline
\end{tabular}

${ }^{\mathrm{T}}$ Efeitos de $\mathrm{FM}=$ fonte de mineral; $\mathrm{C}=$ ciclo de pastejo; $\mathrm{FM} * \mathrm{C}=$ interação fonte de mineral e ciclo de pastejo. ${ }^{2} \mathrm{CV}=$ coeficiente de variação.

*Significativo a $5 \%, * *$ Significativo a $1 \%$.

Houve diferença entre todos os parâmetros analisados com relação aos ciclos de pastejo, de modo podem ser visualizados na Tabela 4, os efeitos significativos $(\mathrm{P}<0,01)$ para massa de forragem, em t de MS /ha, proporções de colmo/bainha, folha e material senescente, altura do dossel na entrada, em $\mathrm{cm}$, oferta de forragem (OF) em $\mathrm{kg}$ $\mathrm{MS} / 100 \mathrm{~kg}$ de PC, oferta de folhas, em $\mathrm{kg}$ de $\mathrm{MS} / 100 \mathrm{~kg}$ de PC (Tabela 3). O ajuste na taxa de lotação realizado ao longo do período experimental, procurando-se manter a mesma oferta de forragem, expressa em $\mathrm{kg}$ de $\mathrm{MS} / 100 \mathrm{~kg}$ de PC entre os tratamentos avaliados, fez com que houvesse variações nas ofertas de forragem entre os diferentes ciclos, cujos valores foram de 20,$7 ; 10,7 ; 6,9 ; 8,4$ e $13,9 \mathrm{~kg}$ de $\mathrm{MS} / 100 \mathrm{~kg}$ de PC para os ciclos de pastejo $1 ; 2 ; 3 ; 4$ e 5 , respectivamente. 
Tabela 4. Valores médios de massa de forragem, em t/ha, proporções (\%) de colmo/bainha, folha e material senescente (M Sen), altura do dossel (AD) na entrada e saída, em cm, oferta de forragem (OF) e oferta de folhas (OFF), em $\mathrm{kg}$ de MS/100 kg de PC da pastagem de Brachiaria brizantha, cv. Marandu durante a época das águas em função dos ciclos de pastejo

\begin{tabular}{|c|c|c|c|c|c|c|c|}
\hline \multirow{2}{*}{ Variáveis } & \multicolumn{5}{|c|}{${\text { Ciclos de pastejo }(\mathrm{C})^{1}}^{1}$} & \multirow{2}{*}{ Média } & \multirow{2}{*}{$\mathrm{CV}^{2}$} \\
\hline & 1 & 2 & 3 & 4 & 5 & & \\
\hline Massa de forragem & $7,3^{\mathrm{a}}$ & $5,6^{\mathrm{b}}$ & $6,8^{\mathrm{ab}}$ & $7,2^{\mathrm{a}}$ & $7,8^{\mathrm{a}}$ & 6,93 & 18,9 \\
\hline Colmo/bainha & $13,2^{\mathrm{c}}$ & $31,4^{\mathrm{b}}$ & $35,7^{\mathrm{ab}}$ & $44,5^{\mathrm{a}}$ & $31,8^{\mathrm{b}}$ & 31,3 & 32,4 \\
\hline Folha & $18,5^{\mathrm{d}}$ & $32,9^{\mathrm{ab}}$ & $41,2^{\mathrm{a}}$ & $29,6^{\mathrm{b}}$ & $26,8^{\mathrm{bc}}$ & 29,8 & 36,3 \\
\hline M Sen & $68,3^{\mathrm{a}}$ & $35,7^{\mathrm{b}}$ & $23,0^{\mathrm{c}}$ & $25,9^{\mathrm{bc}}$ & $41,4^{\mathrm{b}}$ & 38,9 & 36,6 \\
\hline AD entrada & $48,6^{\mathrm{b}}$ & $62,3^{\mathrm{a}}$ & $60,9^{\mathrm{a}}$ & $52,3^{\mathrm{b}}$ & $42,2^{\mathrm{c}}$ & 53,3 & 14,3 \\
\hline AD saída & $29,2^{\mathrm{b}}$ & $32,8^{\mathrm{a}}$ & $32,9^{\mathrm{a}}$ & $32,1^{\mathrm{ab}}$ & $32,5^{\mathrm{a}}$ & 32,1 & 18,1 \\
\hline OF & $20,7^{\mathrm{a}}$ & $10,7^{\mathrm{c}}$ & $6,9^{\mathrm{d}}$ & $8,4^{\mathrm{d}}$ & $13,1^{\mathrm{b}}$ & 12,0 & 24,5 \\
\hline OFF & $3,51^{\mathrm{a}}$ & $3,49^{\mathrm{a}}$ & $2,74^{\mathrm{bc}}$ & $2,43^{c}$ & $3,44^{\mathrm{ab}}$ & 3,12 & 28,9 \\
\hline
\end{tabular}

Médias seguidas da mesma letra minúscula na linha não diferem entre si pelo teste Tukey $(\mathrm{P}>0,05)$.

${ }^{1}$ Ciclos de pastejo $=1(09 / 10 / 06$ a 19/11/06); $2(20 / 11 / 06$ a $31 / 12 / 06) ; 3(01 / 01 / 07$ a $11 / 02 / 07) ; 4$ $(12 / 02 / 07$ a $25 / 03 / 07)$ e $5(26 / 03 / 07$ a $07 / 05 / 07)$

${ }^{2} \mathrm{CV}=$ coeficiente de variação.

No primeiro ciclo de pastejo, os valores médios de material senescente $(68,3 \%)$ foram elevados, provavelmente em função de menores ocorrências de chuvas neste período (Figura 1), caracterizando a forragem como de baixa qualidade, em termos nutricionais, evidenciado pelo baixo teor de $\mathrm{PB}$ e elevado de FDN (Tabela 2), fato este colaborado pela proporção de folhas $(18,5 \%)$ observadas no pasto e também com a elevada oferta de forragem (Tabela 4). As variações nos índices pluviométricos ao longo do período experimental (Figura 1) provocaram mudanças nas proporções de colmo/bainha, folha e material senescente. A maior incidência de chuvas nos ciclos de pastejo 2 e 3 (Figura 1) propiciou aumento na proporção de folhas e redução na proporção de material senescente nestes ciclos (Tabela 4) e proporcionou melhor valor nutricional a forragem (Tabela 2).

Os ajustes na taxa de lotação foram realizados ao longo do período experimental (ciclos de pastejo), procurando-se manter a mesma oferta entre os tratamentos, fato este conseguido com o manejo adotado (Tabela 3). A taxa média de lotação no final do período experimental foi de $4,19 \mathrm{UA} / \mathrm{ha}$. Este resultado foi superior ao relatado por Flores et al. (2008) que encontraram taxa de lotação média de 3,4 UA/ha, na época das águas, em pasto de capim Marandu manejado com altura do dossel, na entrada, de $40 \mathrm{~cm}$.

Verificou-se que o desempenho (GMD, incremento na altura da cernelha $\mathrm{e}$ perímetro torácico) das novilhas que receberam suplemento com fontes de minerais inorgânicos não diferiu $(\mathrm{P}>0,05)$ daquelas que receberam minerais orgânicos e o consumo médio do suplemento foi de 58,10 e $57,12 \mathrm{~g} / \mathrm{animal} / \mathrm{dia}, \quad$ respectivamente (Tabela 5).

Com relação aos ciclos de pastejo, houve diferença $(\mathrm{P}<0,05)$ no GMD, com melhores e pior desempenho no segundo e quinto e no quarto 
Rev. Bras. Saúde Prod. Anim., Salvador, v.14, n.2, p.336-349 abr./jun., 2013 http://www.rbspa.ufba.br ISSN 15199940

ciclo, respectivamente, justificado, provavelmente, pela maior oferta de folhas $(3,49$ e $3,44 \mathrm{~kg} \mathrm{MS} / 100 \mathrm{~kg}$ de PC) no segundo e quinto ciclos, respectivamente, e maior proporção de colmo/bainha $(44,5 \%)$, potencialmente não consumido pelos animais no quarto ciclo de pastejo. Além disso, o melhor valor nutritivo da forragem no segundo e quinto ciclos $(6,5$ e $5,6 \%$ de $\mathrm{PB}$ e 64,9 e $66,7 \%$ de FDN, respectivamente) em comparação ao quarto ciclo $(5,2 \%$ de PB e $66,1 \%$ de FDN) pode de contribuído para o maior desempenho dos animais. Com o ajuste na taxa de lotação efetuada no quarto ciclo de pastejo, aumentou-se no quinto ciclo, a oferta de MS e de folhas (Tabela 5), expressas em $\mathrm{kg} / 100 \mathrm{~kg}$ de $\mathrm{PC}$, melhorando o valor nutritivo da forragem (Tabela 2) e, consequentemente, o GMD (Tabela 5). Outro fator a ser levado em consideração foi a falta de chuvas ocorrida, principalmente, nos meses de março e abril de 2007, impactando no desenvolvimento da gramínea (Figura 1).

Tabela 5. Ganho médio diário $(\mathrm{GMD})$, perímetro torácico $(\mathrm{cm})$ e altura na cernelha (cm) de novilhas mestiças e as respectivas médias e coeficientes de variação (CV) durante a época das águas em função da fonte utilizada na suplementação mineral

\begin{tabular}{|c|c|c|c|c|c|c|}
\hline \multirow{3}{*}{ Fonte mineral } & \multicolumn{5}{|c|}{ Ciclos de pastejo } & \multirow{3}{*}{ Médias } \\
\hline & 1 & 2 & 3 & 4 & 5 & \\
\hline & $20 / 11 / 06$ & $01 / 01 / 07$ & $12 / 02 / 07$ & $26 / 03 / 07$ & $07 / 05 / 07$ & \\
\hline & \multicolumn{6}{|c|}{ GMD $\left(\mathrm{kg} \mathrm{dia}^{-1}\right)$} \\
\hline Inorgânico & 0,670 & 0,906 & 0,575 & 0,397 & 0,794 & $0,668^{\mathrm{A}}$ \\
\hline Orgânico & 0,568 & 0,903 & 0,691 & 0,509 & 0,806 & $0,695^{\mathrm{A}}$ \\
\hline Médias & $0,619^{b}$ & $0,904^{\mathrm{a}}$ & $0,633^{\mathrm{b}}$ & $0,452^{\mathrm{c}}$ & $0,800^{\mathrm{a}}$ & 0,678 \\
\hline \multirow[t]{2}{*}{$\mathrm{CV}$} & - & - & - & - & - & 25,77 \\
\hline & \multicolumn{6}{|c|}{ Perímetro torácico $(\mathrm{cm})$} \\
\hline Inorgânico & 5,48 & 8,75 & 7,31 & 2,04 & 5,05 & $5,73^{\mathrm{A}}$ \\
\hline Orgânico & 5,96 & 7,69 & 8,06 & 2,75 & 5,39 & $5,97^{\mathrm{A}}$ \\
\hline Médias & $5,72^{\mathrm{b}}$ & $8,22^{\mathrm{a}}$ & $7,69^{\mathrm{a}}$ & $2,39^{\mathrm{c}}$ & $5,22^{\mathrm{b}}$ & 5,86 \\
\hline \multirow[t]{2}{*}{$\mathrm{CV}$} & - & - & - & - & - & 44,47 \\
\hline & \multicolumn{6}{|c|}{ Altura na cernelha $(\mathrm{cm})$} \\
\hline Inorgânico & 6,44 & 3,88 & 1,52 & 1,71 & 3,54 & $3,42^{\mathrm{A}}$ \\
\hline Orgânico & 5,02 & 3,94 & 2,43 & 1,71 & 2,81 & $3,18^{\mathrm{A}}$ \\
\hline Médias & $5,73^{\mathrm{a}}$ & $3,01^{b}$ & $1,98^{\mathrm{c}}$ & $1,71^{\mathrm{c}}$ & $3,17^{\mathrm{b}}$ & 3,31 \\
\hline $\mathrm{CV}$ & - & - & - & - & - & 55,30 \\
\hline
\end{tabular}

Médias seguidas da mesma letra maiúscula na coluna e minúscula na linha não diferem entre si pelo teste Tukey $(\mathrm{P}>0,05)$.

Há na literatura, poucos trabalhos avaliando o desempenho de novilhas leiteiras suplementadas com sal mineral contendo fontes orgânicas. Não foram verificados efeitos das fontes de minerais no desenvolvimento corporal das novilhas e o ganho de peso foi, em média, 0,678kg/animal $/$ dia. Este resultado foi inferior ao relatado por Flores et al. (2008), que em pasto de capim Marandu manejado para a entrada dos animais com altura do 
dossel de $40 \mathrm{~cm}$, verificaram GMD de $0,800 \mathrm{~kg} / \mathrm{animal} / \mathrm{dia}$, mas com menor taxa de lotação. No entanto, ganho médio de $500 \mathrm{~g} /$ dia do nascimento até a concepção, para novilhas mestiças Holandês $\mathrm{x}$ Zebu é considerado adequado (CAMPOS \& LIZIEIRE, 2005).

Os resultados de pesquisa tem sido contraditório quando se avaliam a atuação de fontes de minerais orgânicos tanto na produção quanto na reprodução animal (SPEARS \& KEGLEY, 2002; WARD et al. 2002; VILELA, et al., 2011) e poucos são os trabalhos na literatura avaliando fontes de minerais orgânicos na suplementação de novilhas leiteiras.

No entanto, provavelmente, a ausência de diferença no desempenho das novilhas pelas fontes de minerais foi em virtude do desconhecimento do mecanismo de ação dos minerais complexados, porém supõe-se que os mesmos apresentem maior biodisponibilidade no trato gastrintestinal, melhorando a absorção e o desempenho produtivo e reprodutivo dos animais. Além disso, a biodisponibilidade destas fontes de minerais é influenciada por diversos fatores, tais como: tamanho de partícula, reatividade e solubilidade, origem do precursor, grau de calcinação e ligantes orgânicos, o que pode contribuir para as variações nas respostas de desempenho dos animais (SPEARS, 2003; ZANETTI, et al., 2003).

$\mathrm{O}$ peso vivo médio inicial dos animais experimentais foi de $176,8 \mathrm{~kg}$ e o final foi de $322,8 \mathrm{~kg}$ (sal mineral orgânico) e $317,36 \mathrm{~kg}$ (sal mineral inorgânico), os quais não diferiram entre si. Considerando o peso médio final $(320,14 \mathrm{~kg})$ e inicial $(176,8 \mathrm{~kg})$ dos animais, houve um acúmulo de peso de $143,3 \mathrm{~kg}$ em 210 dias. Para o tipo de animais utilizados no presente experimento (fêmeas mestiças Holandês $\mathrm{x}$ Zebu), a recomendação de peso para inicio do período de cobertura seria de $330 \mathrm{~kg}$ (CAMPOS \& LIZIEIRE, 2005). Assim para alcançar o peso ideal a cobertura, as possibilidades seriam melhorar o peso a desmama ou adotar estratégias de suplementação durante a época da seca pós-desmama.

Vale ressaltar, que o manejo adotado, utilizando-se suplementação mineral para atender as exigências dos animais, associado ao bom manejo do pasto na época das águas é capaz de propiciar as condições necessárias para crescimento satisfatório das novilhas (DOMINGUES et al., 2008). Outro ponto a ser ressaltado, é o potencial da gramínea utilizada no presente trabalho $(B$. Brizantha, cv. Marandu), a qual, se bem manejada, propicia produção de forragem em quantidade e de qualidade e, consequentemente, resultará em bom desempenho animal durante a época das águas.

Segundo Macdonald et al. (2005) e Davis Rincker et al. (2011), os animais submetidos a baixo nível nutricional tiveram atraso na idade à puberdade não apresentaram cio até que o seu peso corporal fosse similar ao peso dos animais ao primeiro cio que receberam nível nutricional normal e alto, reforçando, assim, a influência do peso no desenvolvimento reprodutivo dos animais. A taxa de crescimento das bezerras e novilhas é excelente indicador do nível de manejo adotado na propriedade. Tem sido relatado que ganhos de peso abaixo de $0,35 \mathrm{~kg} / \mathrm{dia}$ e acima de $0,95 \mathrm{~kg} /$ dia comprometem a idade, a maturidade sexual e podem prejudicar a futura produção de leite, por acúmulo de gordura no úbere. $\mathrm{O}$ desempenho de novilhas leiteiras recriadas a pasto foi semelhante quando 
Rev. Bras. Saúde Prod. Anim., Salvador, v.14, n.2, p.336-349 abr./jun., 2013 http://www.rbspa.ufba.br ISSN 15199940

suplementadas com fontes minerais inorgânicos ou orgânicos.

\section{AGRADECIMENTOS}

Ao CNPq e a Tortuga Cia Zootecnica Agrária pelo apoio e suporte financeiro dado a pesquisa.

\section{REFERÊNCIAS}

BENETT, C.G.; BUZETTI, S.; SILVA, K.S.; BERGAMACHINE, A.F.; FABRÍCIO, J.A. Produtividade e composição bromatológica do capim Marandu a fontes e doses de nitrogênio. Ciência Agrotecnologia, v.32, n.5, p.1629-1636, 2008.

BRÂNCIO, P.A.; NASCIMENTO JUNIOR, D.; EUCLIDES, V.P.B.; FONSECA, D.M.; ALMEIDA, R.G.; MACEDO, M.C.M.; BARBOSA, R.A. Avaliação de três cultivares de Panicum maximum Jacq. sob pastejo: composição da dieta, consumo de matéria seca e ganho de peso animal. Revista

Brasileira de Zootecnia, v.32, n.5, p.1037-1044, 2003.

CAMPOS, O.F.; LIZIEIRE, R.S. Criação de bezerras em rebanhos leiteiros. Juiz de Fora: Embrapa Gado de leite, 2005. $142 \mathrm{p}$.

DAVIS RINCKER, L.E.; VANDEHAAR, M.J.; WOLF, C.A.; LIESMAN, J.S.; CHAPIN, L.T.; WEBER NIELSEN, M.S. Effect of intensified feeding of heifer calves on growth, pubertal age, calving age, milk yield, and economic. Journal of Dairy Science, v.94, n.7, p.3354-3367, 2011.
DESCHAMPS, F.C. Implicações do período de crescimento na composição química e digestão dos tecidos de cultivares de capim elefante. Revista Brasileira de Zootecnia, v.28, n.6, p.1178-1189, 1999.

DOMINGUES, F.N., SILVA, J.F.C., VASQUEZ, H.M.; VIEIRA, R.A.M.; FEROLLA, F.S.; LISTA, F.N.

Desempenho ponderal de novilhas mestiças Holandês x Zebu submetidas a duas estratégias de suplementação mineral. Revista Brasileira de Zootecnia, v.37, n.2, p.343-349, 2008.

EUCLIDES, V.P.B. Alternativas para intensificação da produção de carne bovina em pastagem. Campo Grande: Embrapa Gado de Corte, 2000. 65p.

FILAPPI, A.; PRESTES, D.; CECIM, M. Suplementação mineral para bovinos de corte sob pastejo - revisão. Veterinária Notícias, v.11, n.2, p.91-98, 2005.

FLORES, R.S.; EUCLIDES, V.P.B.; ABRÃO, M.P.C.; GALBEIRO, S.; DIFANTE, G.S.; BARBOSA, R.A. Desempenho animal, produção de forragem e características estruturais dos capins marandu e xaraés submetidos a intensidades de pastejo. Revista Brasileira de Zootecnia, v.37, n.8, p.1355-1365, 2008.

HODGSON, J. Grazing management: science into practice. New York: Longman Scientific \& Technical, 1990. 203p.

LAZZARINI, I.; DETMANN, E.; SAMPAIO, C.B.; PAULINO, M.F.; VALADARES FILHO, S.C.; SOUZA, M.A.; OLIVEIRA, F.A. Intake and digestibility in cattle fed low-quality tropical forage and supplemented with nitrogenous compounds. Revista Brasileira de Zootecnia, v.38, n.10, p.2021-2030, 2009. 
MACDONALD, K,A.; PENNO, J.W.; BRYANT, A.M.; ROCHE, J.R. Effect of feeding level pre and post-puberty and body weight at first calving on growth, milk production, and fertility in grazing Dairy cows. Journal of Dairy Science, $v$. 88, n.9, p.3363-3375, 2005.

PAULA, N.F.; ZERVOUDAKIS, J.T.; CABRAL, L.S.; CARVALHO, D.M.G.; HATOMOTO-ZERVOUDAKIS, L.K.; MORAES, E.H.B.K.; OLIVEIRA, A.A. Frequência de suplementação e fontes de proteína para recria de bovinos em pastejo no período da seca: desempenho produtivo e econômico. Revista

Brasileira de Zootecnia, v.39, n.4, p.873-882, 2010.

PEIXOTO, P.V.; MALAFAIA, P.; BARBOSA, J.D.; TOKARINA, C.H. Princípios de suplementação mineral em ruminantes. Pesquisa Agropecuária Brasileira, v.25, n.3, p.195-200, 2005.

PERES, A.A.C.; SOUZA, P.M.; VASQUEZ, H.M.; COELHO DA SILVA, J.F.; HADDADE, I.R.; LISTA, F.N. Custo de produção na recria de novilhas mestiças Holandês x Zebu em pastagem de capim-elefante. Boletim de Indústria Animal, v.65, n.2, p.99-108, 2008.

REIS, R.A.; RUGGIERI, A.C.; CASAGRANDE, D.R.; PÁSCOA, A.G. Suplementação da dieta de bovinos de corte como estratégia do manejo das pastagens. Revista Brasileira de Zootecnia, v.38. p.147-159, 2009.

SAMPAIO, C.B.; DETMANN, E.; LAZZARINI, I.; SOUZA, M.A.; PAULINO, M.F.; VALADARES FILHO, S.C. Rumen dynamics of neutral detergent fiber in cattle fed low-quality tropical forage and supplemented with nitrogenous compounds. Revista Brasileira de Zootecnia, v.38, n.3, p.560-569, 2009.
SAS Institute. Online DOC. Version 8. Cary, 1999.

SILVA, D.J.; QUEIROZ, A.C. Análises de alimentos: métodos químicos e biológicos. 3.ed. Viçosa: Universidade Federal de Viçosa, 2002. 165 p.

SPEARS, J.W. Trace mineral bioavailability in ruminants. Journal of Nutrition, v.133, n.5, p.1506-1509, 2003.

SPEARS, J.W.; KEGLEY, E.B. Effect of zinc (source oxide vs zinc proteinate) and level on performance, carcass characteristics, and immune response of growing and finishing steers. Journal of Animal Science, v.80, n.11, p.27472752, 2002.

Van SOEST, P.J.; ROBERTSON, J.B.; LEWIS, B.A. Methods for dietary fiber, neutral detergent fiber, and nonstarch polyssacarides in relation to animal nutrition. Journal of Dairy Science, v.74, n.10, p.3583-3597, 1991.

VILLELA, S.D.J.; PAULINO, M.F.; VALADARES FILHO, S.C.; DETMANN, E.; VALADARES, R.F.D.; ARAÚJO, K.G. Suplementação para bovinos em pastejo no período de transição águas-seca: variáveis nutricionais. Revista Brasileira de Saúde e Produção Animal [online], v.11, n.4, p.1033-1045, 2010.

VILELA, F.G.; ZANETTI, M.A.; SARAN NETTO, A.; FREITAS JÚNIOR, J.E.; RENNÓ, F.P.; BARLETTA, R.V. Suplementação de dietas para bezerros nelore recémdesmamados com fontes de zinco orgânica e inorgânica. Revista Brasileira de Saúde e Produção Animal [online], v.12, n.4, p.10081015, 2011. 
WARD, J.D.; SPEARS, J.W.;

KEGLEY, E.B. Effect of trace mineral source on mineral metabolism, performance and immune response in stressed cattle. Journal of Animal

Science, v.80, n.1, p.300, 2002.

Suppl.1.

ZANETTI, M.A.; SALES, M.S.V.;

BRISOLA, M.L.; CÉSAR, M.C.

Desempenho e resposta metabólica de

bezerros recebendo dietas

suplementadas com cromo. Revista

Brasileira de Zootecnia, v.32, n.6, p.1532-1535, 2003.

Data de recebimento: $29 / 08 / 2012$

Data de aprovação: 05/06/2013 